OPEN ACCESS

Edited by:

Subimal Ghosh,

Indian Institute of Technology

Bombay, India

Reviewed by:

Tafadzwanashe Mabhaudhi, University of KwaZulu-Natal,

South Africa

Mohit Mohanty,

University of Western

Ontario, Canada

*Correspondence:

Hugo G. Hidalgo

hugo.hidalgo@ucr.ac.cr

Specialty section:

This article was submitted to

Water and Climate,

a section of the journal

Frontiers in Water

Received: 23 November 2020 Accepted: 28 December 2020 Published: 22 January 2021

Citation:

Hidalgo HG (2021) Climate Variability and Change in Central America: What

Does It Mean for Water Managers?

Front. Water 2:632739.

doi: 10.3389/frwa.2020.632739

\section{Climate Variability and Change in Central America: What Does It Mean for Water Managers?}

\author{
Hugo G. Hidalgo ${ }^{1,2 *}$ \\ ${ }^{1}$ Center for Geophysical Research and School of Physics, University of Costa Rica, San Jose, Costa Rica, ${ }^{2}$ Focal Point, \\ Water Program of the International Network of Academies of Science, San Pedro, Costa Rica
}

Central America is a unique climate region in the world, due to its location and shape, as well as the many large and local scale climate processes that influence its variability and change at a large range of spatial and time scales. Observed temperature trends have been increasing significantly and they are expected to increase even more in the future, potentially increasing aridity. Managers should make an informed decision on whether a sophisticated modeling approach is best for your region, or simpler approaches are available for determining shorter term planning. Always ask and question the uncertainty of information that is presented. Use this modeling information as a dynamic and constantly changing effort, as future evolves new analysis would need to be performed as models and data become more accurate.

Keywords: climate, modeling, Americas, uncertainty, planning

\section{INTRODUCTION}

Central America is a unique climatic region in the world. Located in a tropical setting, the isthmus constitutes a stretch of land of complex topography between the Pacific Ocean and the Caribbean Sea. Large-scale natural climate processes originated in these two water bodies greatly influence the continental climate. Examples of those processes are El Niño-Southern Oscillation (ENSO); the trade winds influence expressed in the Caribbean Low-Level Jet; the Intertropical Convergence Zone; the North Atlantic Subtropical High; and many others.

Although the presence of abundant micro-climates is a defining characteristic of the region, it is common to classify the climate into having predominantly Pacific or Caribbean slope features. The Pacific climate has a well-defined dry season lasting 4-6 months, while the Caribbean climate has wet characteristics all year long. In general, the El Niño (warm phase of ENSO) events are associated with dry conditions in the Pacific slope and wet conditions in the Caribbean slope and vice versa for La Niña events. The ENSO signal and its impacts are reinforced when the sea surface temperature anomalies in the Pacific coast and the Caribbean coast anomalies are of opposite signs.

Even when one considers only natural climate forcings, the variability at a large range of spatial (e.g., mesoscale, synoptic, global) and time scales (e.g., daily, intra-seasonal, interannual, decadal, multidecadal) is very high in the region. Extreme events associated with natural phenomena such as tropical cyclones, ENSO, cold-fronts, easterly waves and many others, produce severe environmental and socioeconomic impacts in a region that is highly vulnerable to droughts and floods. It is estimated that the interannual variability represents $84 \%$ of the total variability in precipitation, while the decadal component amounts to $14 \%$ and the trend only $2 \%$ (Greene et al., 2011; Hidalgo-León et al., 2015). Therefore, preparing for precipitation's natural variability 
is an excellent step forward toward the adaptation for anthropogenic climate change. However, one has to take into consideration in this picture that observed trends in temperature have been increasing significantly in many parts of Central America (Hidalgo et al., 2019; Alfaro-Córdoba et al., 2020). Even without significant precipitation changes, increased temperatures can produce a higher demand of water from the atmosphere, drier soils and higher aridity, which can impact, for example, agriculture, the environment and wildfire's potentials. Research (Alfaro-Córdoba et al., 2020) has shown that aridity has been increasing significantly at isolated spots in Central America, but the consistent temperature trends (1970-1999) were still not sufficient to drive widespread aridity changes during the same study period. This may have changed during the most recent period; for this reason more research is needed in order to verify the significance of such trends.

Observed trends in temperature extreme indices for at least the last 25 years have shown that minimum temperatures have been registering widespread extremes toward a higher frequency of warm nights and lower frequency of cold nights. Conversely, maximum temperatures do not exhibit such robust trends, and depend greatly on the database used. Overall, it can be concluded that the most robust signal is that nighttime temperatures are significantly increasing. For precipitation, station data (19792010) have shown inconsistent trends in extreme indices, with the exception of Costa Rica, where a group of several stations suggest an increase in the intensity of extremely high precipitation events.

Climate and hydrological models have been used to project possible climate changes associated with natural and anthropogenic causes in the region (Hidalgo et al., 2013; Hidalgo and Alfaro, 2017). These models have shown deficiencies in reproducing regional precipitation patterns, but they reproduce quite well temperature patterns (Hidalgo and Alfaro, 2015). This is an important limitation when considering the use of these models for management and adaptation purposes. It is recommended that the information that is provided by the models should be used a general guide of what will probably occur in the future, using the information that has lower uncertainty. For example, considering the most aggressive emission scenario most of the models suggest that the temperature in the region is going to increase at least $2^{\circ} \mathrm{C}$ by mid-century and over $4^{\circ} \mathrm{C}$ at the end compared to the baseline period (1970-1999), while precipitation is not going to change much over the first half of the century and then decrease about $10 \%$ at the end; especially in the northern part of Central America. Under these scenarios, and considering the reasons explained before, one can think that aridity is going to increase significantly, in particular for the northern countries and this can have important socioeconomic impacts especially considering that in most Central American countries agriculture is the principal productive sector of the economy. One must consider that there is already a north-south socioeconomic gradient in the region and climate change may exacerbate this contrast (Hidalgo and Alfaro, 2012) which can result in larger inequality, increased migration, higher vulnerability to disasters and poverty.

\section{POLICY OPTIONS, IMPLICATIONS, AND ACTIONS}

Some adaptation strategies in the world including Central America have been based on global climate model simulations and regionalization by dynamical or statistical methods. The resulting local future climate has been used in other models, or directly as a guide to define mid-term and long-term policies. Although climate models are state of the art simulations of the climate and are an excellent guide for what may come in the future; this approach, needs a previous evaluation if its use is convenient for the specific location or if its limitations have been clearly stated to stakeholders and managers (Nissan et al., 2019).

The official source of climate change projections in the region is the occasional publication of climate change reports from the meteorological and hydrological services of the region. These reports are used by governmental and non-governmental organizations to guide climate change adaptation plans. Other sources of climate change projections data are produced by the universities, which are used mainly in academic articles and reports, but sometimes the information is also used in adaptation plans. Every 2-3 months, the Central America Climate Applications Forum (a regional institution part of the Central American Integrated System) meets in one of the member countries to discuss issues related to climate, in particular applications of seasonal forecasting outlooks, but also climate variability and change issues are included. Each country, however, has different approaches to define their specific policies in national adaptation strategies, usually framed into the emergency programs and institutions. For this reason, the forum is a valuable opportunity to strengthen collaboration between the countries for the interchange of experiences, data and knowledge of the different adaptation plans and studies.

In many countries the adaptation strategies are produced at a municipality level, supported by local studies focused on the determination of risk and possible observed and future impacts of climate in different types of socioeconomic sectors. There is a need for a digital repository of the many local studies that have been produced in the Central America countries, as there are a lot of academic articles and gray literature that are unavailable to managers. Also, it is necessary the creation of a uniform methodology for computing climate variability and change risk assessments for all the municipalities within a country, and the involvement of managers and stakeholders in constructing adaptation plans at several time horizons. As it will be mentioned later, these risk assessments should consider their uncertainty, horizon and scale, as these issues must be translated to managers along with the adaptation plan. There are also issues of water governance that need to be resolved in several countries of the region, as there are many national institutions with different interests in the resource (e.g., ministries, municipalities, municipal councils, local water associations, autonomous institutions, nongovernmental organizations), which results in difficulties for decision making. General climate change policies are usually issued by the National Ministry of the Environment or equivalent 
institution in Costa Rica, Guatemala, El Salvador, Belize and Honduras; by the National Environment Authority in Panama, or directly by the Presidency of the Republic in Nicaragua. However, there are also policies derived from independent adaptation studies. In all cases, there is a need of a better communication between the many stakeholders in order to optimize resources and support better decisions.

An example of the general policies produced by the government in Costa Rica can be found in the National Adaptation Policy. Such policy is contained in the National Adaptation Plan (Ministerio de Ambiente y Energía, 2018), which identified six general types of problems associated with climate change: (1) agriculture and fisheries, (2) water resources, (3) biodiversity, (4) health, (5) infrastructure and (6) development of territories and tourism. In Panama, the National Policy in Climate Change ${ }^{1}$ has objectives in the development of (1) institutional framework, (2) environmental management, (3) normative scope and (4) citizen participation. In Nicaragua the policy is centered in five principles $^{2}$ : (1) acknowledgment of traditional knowledge, (2) ecosystem focus, (3) synergies and complementarity between mitigation and adaptation, (4) inclusion and citizen participation, and (5) prioritizing economy based on agriculture, fisheries and livestock. In Honduras (Secretaría de Recursos Naturales y Ambiente, 2010), the policies have seven focus areas: (1) water resources, (2) agriculture, soils and food security, (3) forests and biodiversity, (4) coastal and marine systems, (5) human health, (6) risk management and (7) hydropower. In Guatemala (Ministerio de Ambiente y Recursos Naturales, 2009), the policies are categorized in six themes: (1) mitigation, (2) adaptation improvement, (3) capacity building, (4) technologies transference, (5) risk management and (6) vulnerability reduction. In El Salvador ${ }^{3}$ the policies are aimed at reversing the environment degradation and reducing climate change vulnerability. Six specific objectives are related to (1) reversing ecosystem degradation, (2) reversing the environment insalubrity, (3) produce a sustainable water resources management, (4) territorial ordering, (5) promote a culture of environmental responsibility and (6) reducing climate risk. In Belize (Caribbean Community Climate Change Centre, 2014) the policy has eight objectives: (1) integration of mitigation and adaptation, (2) building climate change resilience, (3) promote capacity building, (4) capitalize on opportunities, (5) ensure that all national sectors are adequately prepared to the impacts of climate change, (6) encourage private and public sectors participation, (7) enhance diplomatic and negotiating capabilities and (8) promote the development of efficient and relevant institutional mechanisms. As can be seen, although there are some common themes, the climate change plans for the countries also present different foci in the way the climate change adaptation should be approached. In all cases, however, it is evident that climate, social and land surface data are needed in order to provide better assessments of the possible impacts

\footnotetext{
${ }^{1}$ https://plataformacelac.org/en/politica/483

${ }^{2}$ http://www.snip.gob.ni/Docs/capacitaciones/tallerInter/Nic_PoliticaNacional. pdf

${ }^{3}$ https://plataformacelac.org/en/politica/454
}

and adaptation measures. In the following section some general recommendations will be provided for improving studies that could potentially produce better adaptation plans.

\section{ACTIONABLE RECOMMENDATIONS}

Due to their climatic features, several subregions within Central America present special challenges in terms of their management. For example, the area known as the Central America Dry Corridor (CADC) (Hidalgo et al., 2019), starting in Chiapas in southern Mexico and covering most of the Pacific slope of Central America down to Guanacaste province in Costa Rica (also including the Dry-Arc in Panama), is known for its higher aridity compared to the rest of the isthmus and for being strongly correlated to ENSO and to the strength of the trade winds from the Caribbean. Socioeconomic vulnerabilities are common in the CADC, as subsistence agriculture is one of the main economic activities. It is known that the delimitation of the CADC have a large year-to-year variability (QuesadaHernández et al., 2019). Also, it is important to study the future expansion of the aridity associated with warmer temperatures, as this may signal possible associated impacts in human and environmental systems at the borders of the CADC. These are management challenges that need to be resolved at national and regional level, as the CADC present both common and different problems across the countries. Immigration, poverty, lack of opportunities, population growth, economic development and other national and transboundary issues can become part of the vulnerabilities that along with the climate hazard produce higher risk to extreme events. Therefore, management that takes into consideration hydroclimatological risks should intrinsically consider social aspects that form part of the vulnerability (Hidalgo and Alfaro, 2012).

Other parts of the region have been identified for their vulnerability to extreme wet precipitation events associated with direct and indirect impacts of tropical cyclones (Hidalgo et al., 2020). These critical areas of the cyclones' trajectories cause the higher number of extreme precipitation events in the Caribbean coast of northern Central America (direct impacts) and in the Pacific coast of southern Central America (indirect impacts), while the middle part (i.e., Nicaragua) is being exposed to both types of effects depending on the location of the cyclone. Year after year extreme events are already part of climate variability in the region and produce impacts in diverse sectors of the isthmus (Pérez-Briceño et al., 2016). Management can benefit greatly from adopting more and more impact-based weather, subseasonal and seasonal forecasts. ENSO-based forecasts, for example, have not being used at their full potential, particularly because some of the forecasts are not tied to an associated impact or risk, an application to a certain sector has not being developed and are mainly meteorological in nature. More transdisciplinary and interdisciplinary collaboration is needed between the institutions that issue the forecasts and the final users. As was previously mentioned, preparing for the impacts of this variability provides resilience for future climate change impacts. In terms of climate change projections, the 
recommendations are more elaborated and will be discussed in the rest of this section.

Before investing a lot of resources in a sophisticated modeling effort, stakeholders and managers have to decide first if the modeling approach is consistent with the adaptative capacity of the location given fixed planning horizons. One of the most important issue is to always ask for information about the uncertainty of these estimations and weigh this in the management decisions. A critical approach to the information provided, regarding its suitability for the decision-making, management and uncertainty horizons is necessary. This is especially true in a region of scarce resources as Central America, where optimization of adaptation strategies is crucial.

If a modeling approach is justified, the managers should know that the planning horizons and the modeling horizons could differ, because even as a manager may not be interested in planning horizons of more than say, 15 years; clear climate trends may not arise until periods of at least 30 years are analyzed, as low frequency natural climate variability may obscure these long-term trends and the managers should be aware of them.

The message for managers is to make an informed decision on whether a sophisticated modeling approach for long term planning is best for your region, or whether simpler approaches are available for determining shorter term planning. Always ask and question the uncertainty of information that is presented to you in form of graphs, maps, time-series, etc. considering issues such as future concentration, land use and social scenarios, intermodel differences, methodologies uncertainties, etc. Use this modeling information as a dynamic and constantly changing effort, as future evolves new analysis would need to be performed as models and data become more accurate.

\section{REFERENCES}

Alfaro-Córdoba, M., Hidalgo, H. G., and Alfaro, E. J. (2020). Aridity trends in central america: a spatial correlation analysis. Atmosphere 11:427. doi: $10.3390 /$ atmos 11040427

Caribbean Community Climate Change Centre (2014). A national Climate Change Policy Strategy and Action Plan to Address Climate Change in Belize, 152. Available online at: http://extwprlegs1.fao.org/docs/pdf/blz169290.pdf (accessed December 23, 2020).

Greene, A., Goddard, L., and Cousin, R. (2011). Web tool deconstructs variability in twentieth-century climate. EOS 92, 397-408. doi: 10.1029/2011EO4 50001

Hidalgo, H. G., and Alfaro, E. J. (2012). Some physical and socioeconomical aspects of climate change in Central America. Prog. Phys. Geogr. 36, 379-399. doi: 10.1177/03091333124 38906

Hidalgo, H. G., and Alfaro, E. J. (2015). Skill of CMIP5 climate models in reproducing 20th century basic climate features in Central America. Int. J. Climatol. 35, 3397-3421. doi: 10.1002/joc.4216

Hidalgo, H. G., and Alfaro, E. J. (2017). Observed (1970-1999) Changes in extreme hydroclimatic events in Central America using a high-resolution meteorological dataset with implication to climate change studies. Clim. Change 141, 13-28. doi: 10.1007/s10584-016-1786-y

Hidalgo, H. G., Alfaro, E. J., Amador, J. A., and Bastidas, A. (2019). Precursors of quasi- decadal dry-spells in the Central America Dry Corridor. Clim. Dyn. 53, 1307-1322. doi: 10.1007/s00382-019-04638-y

\section{CONCLUSIONS}

An informed decision for the adaptation to climate variability and change must include understanding of the uncertainty of the different options of analyses that exist for a certain region and budgets. Also, the planning horizons of the climate change adaptation policies influences in part the complexity of the analysis that is needed. Spatial scales of the region of interest and time resolution of the data needed also should be part of the discussions between climate scientists, managers and decision makers.

\section{AUTHOR CONTRIBUTIONS}

The author confirms being the sole contributor of this work and has approved it for publication.

\section{FUNDING}

The research of the author mentioned in the references was funded by the projects B9-454 (VI-Grupos), B8-766 (VI-Redes), B8-604 (Fondo de Estímulo), EC-497 (FEES-CONARE), C0-074, B0-810 and C0-610 (Fondo de Estímulo), from the Center for Geophysical Research (CIGEFI) of the UCR.

\section{ACKNOWLEDGMENTS}

Special thanks to Katherine Vammen and Henry Vaux from IANAS for their help revising and securing publication fee waivers for this article.

Hidalgo, H. G., Alfaro, E. J., Hernández-Castro, F., and PérezBriceño, P. M. (2020). Identification of tropical cyclones' critical positions associated with extreme precipitation events in Central America. Atmosphere 11:1123. doi: 10.3390/atmos111 01123

Hidalgo, H. G., Amador, J. A., Alfaro, E. J., and Quesada, B. (2013). Hydrological climate change projections for Central America. J. Hydrol. 495, 94-112. doi: 10.1016/j.jhydrol.2013.0 5.004

Hidalgo-León, H. G., Herrero-Madriz, C., Alfaro-Martínez, E. J., Muñoz, A. G., Mora-Sandí, N. P., Mora-Alvarado, D. A., et al. (2015). Lasaguas urbanas en Costa Rica. Desafios del agua urbana en las Américas. Mexico: Interamerican Network of Academies of Sciences.

Ministerio de Ambiente y Energía (2018). "Política nacional de adaptación al cambio climático de Costa Rica," in, eds P. O. Girot and I. A. Delgado, 84. Available online at: http://www.pgrweb.go.cr/DocsDescargar/Normas/No \%20DE-41091/Version1/Politica_ADAPTACION_24_abril.pdf (accessed December 23, 2020).

Ministerio de Ambiente y Recursos Naturales (2009). Política Nacional de Cambio Climático, 26. Available online at: http://www.cac.int/sites/default/files/ Politica_Nacional_de_CC.pdf (accessed December 23, 2020).

Nissan, H., Goddard, L., de Perez, E.C., and Furlow, J. (2019). On the use and misuse of climate change projections in international development. WIREs Clim. Change 10:e579. doi: 10.1002/wc c. 579 
Pérez-Briceño, P. M., Alfaro, E. J., Hidalgo, H., and Jiménez, F. (2016). Distribución espacial de impactos de eventos hidrometeorológicos en América Central. Rev. Climatol. 16, 63-75.

Quesada-Hernández, L. E., Calvo-Solano, O. D., Hidalgo, H. G., Pérez- Briceño, P. M., and Alfaro, E. J. (2019). Dynamical delimitation of the Central America Dry Corridor (CADC) using drought indices and aridity values. Prog. Phys. Geogr. 43:030913331986022. doi: 10.1177/0309133319860224

Secretaría de Recursos Naturales y Ambiente (2010). Estrategia Nacional de Cambio Climático Honduras, 46. Available online at: https://www.lse.ac.uk/ GranthamInstitute/wp-content/uploads/laws/8154.pdf (accessed December $23,2020)$.
Conflict of Interest: The author declares that the research was conducted in the absence of any commercial or financial relationships that could be construed as a potential conflict of interest.

Copyright $\odot 2021$ Hidalgo. This is an open-access article distributed under the terms of the Creative Commons Attribution License (CC BY). The use, distribution or reproduction in other forums is permitted, provided the original author(s) and the copyright owner(s) are credited and that the original publication in this journal is cited, in accordance with accepted academic practice. No use, distribution or reproduction is permitted which does not comply with these terms. 